This item was submitted to Loughborough's Institutional Repository (https://dspace.lboro.ac.uk/) by the author and is made available under the following Creative Commons Licence conditions.

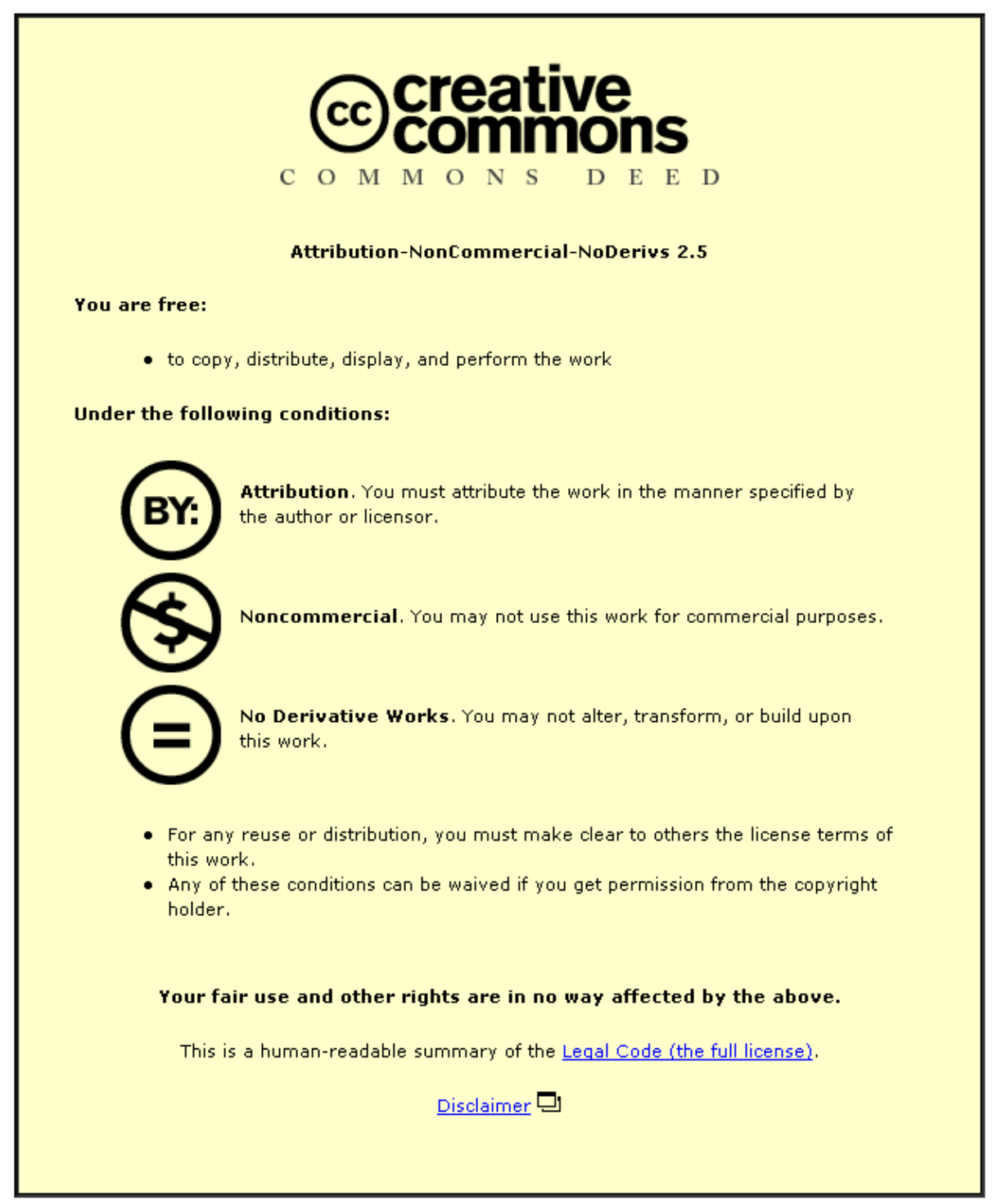

For the full text of this licence, please go to: http://creativecommons.org/licenses/by-nc-nd/2.5/ 


\section{Briefing: Heat-wave-coping measures for housing}

\section{S. Porritt, Institute of Energy and Sustainable Development, De Montfort University; C. I. Goodier, Coventry University; and L. Shao, Institute of Energy and Sustainable Development, De Montfort University}

The effect of climate change is increasingly manifested through more frequent and more intense extreme weather events, including heat waves and flooding. This briefing demonstrates how internal temperatures in housing can be reduced during a heat wave period purely by passive means.

\section{INTRODUCTION}

The research introduced here is part of the Community resilience to extreme weather ${ }^{1}$ (CREW) project. CREW is a multiuniversity, £2 million Engineering and Physical Sciences Research Council (EPSRC)-funded project investigating technological and people-based measures available for adapting the UK built environment to possible future overheating.

The aim of the work is to rank the effectiveness of a variety of passive or near-passive interventions and combinations (clusters) of interventions in reducing summertime overheating in dwellings. A variety of typical house types are being investigated, but initial simulations have concentrated on the most common type of dwelling in the UK, the nineteenthcentury terraced house. The principal research work will use dynamic thermal simulation software to assess the effects of building modifications on internal temperature. Initial results demonstrate that internal temperatures in dwellings during a heat wave can be reduced purely by passive means.

A recent Chartered Institute of Building Services Engineers report ${ }^{2}$ suggested strategies for adapting several building types to cope with predicted future summertime overheating. The report predicted the potential reduction in the percentage of occupied hours over the summer that exceeded comfort threshold temperatures (for dwellings) of $25^{\circ} \mathrm{C}$ for bedrooms and $28^{\circ} \mathrm{C}$ for other rooms. The results are presented as a comparison of current base-case constructions with those that incorporate a collection of interventions depending on building type. The research presented here breaks down the interventions to see the individual and combined effects of different interventions.

\section{METHODOLOGY}

Initial investigations are being carried out using Integrated Environmental Solutions (IES) virtual environment software. In the computer models that are being constructed, the base-case houses are based on site survey plans and construction data, which are then cross-referenced with the Energy Saving Trust's homes energy efficiency database (HEED). ${ }^{3}$ This ensures that the simulation models are representative of the UK housing stock.

The house type presented here is a short row of three terraced houses, constructed in the late nineteenth century (Figure 1). Each house comprises a living room, dining room, kitchen, bathroom and three bedrooms. The walls are solid brick, except for the rear extensions in which the old sculleries have been replaced with uninsulated brick/block cavity walls to form a new kitchen with a bathroom above. The houses have

(a) suspended timber ground floors

(b) uninsulated concrete floors in the rear extensions

(c) single brick/plaster internal partitions

(d) clay tile roofs with $100 \mathrm{~mm}$ of glass fibre loft insulation

(e) pre-2002 PVC framed double glazing to all windows.

Internal gains from people and equipment were calculated using reference values from $\mathrm{CIBSE}^{4}$ and American Society of Heating, Refrigerating and Air-Conditioning Engineers. ${ }^{5}$ The occupancy patterns (for two adults and two children) assumed that the houses were unoccupied during the day.

In order to simulate the thermal performance of the houses in hot summer weather conditions, a future weather file based on the predicted weather in the 2080s under the UK climate impacts programme (UKCIP02) ${ }^{6}$ medium-high emissions

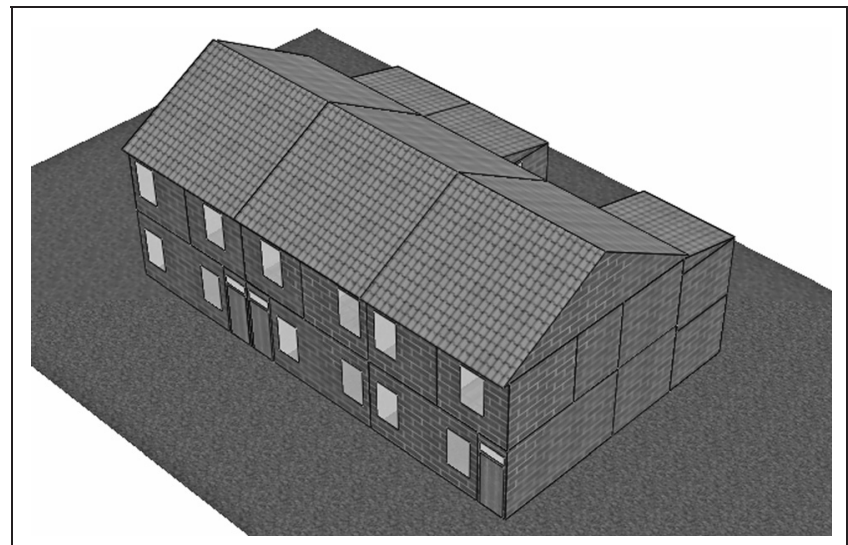

Figure I. Typical terraced houses modelled using IES virtual environment software 
scenario was used. The simulation run uses a ten-day preconditioning period, so a summer period in early August of reasonably consistent hot weather was chosen. The effect of a range of single interventions, including those shown in Table 1, was modelled to determine the most effective adaptation strategy.

\section{RESULTS}

The operative temperature for each room was simulated for a summer date (10 August). Figure 2 shows the effect of a few selected single interventions on the operative temperature in bedroom 1 of house 1 over the $24 \mathrm{~h}$ of 10 August.

Figure 3 shows that the best single interventions (as listed in Table 1) for both bedrooms and living rooms are the use of external shutters and painting exterior walls a light colour that is, both measures reduce the effect of direct solar gain.

\begin{tabular}{|c|c|}
\hline Number & Intervention \\
\hline I & $\begin{array}{l}\text { Change in window opening rules (i.e. do not open it } \\
T_{\text {outside }}>T_{\text {inside }} \text { ) }\end{array}$ \\
\hline 2 & $\begin{array}{l}\text { Night ventilation through open windows on ground } \\
\text { floor }\end{array}$ \\
\hline 3 & Low-e double glazing \\
\hline 4 & Fixed external shading \\
\hline 5 & $300 \mathrm{~mm}$ loft insulation \\
\hline 6 & Light-coloured roof \\
\hline 7 & Internal wall insulation \\
\hline 8 & Internal blinds \\
\hline 9 & External shutters \\
\hline 10 & Light-coloured walls \\
\hline II & External wall insulation \\
\hline
\end{tabular}

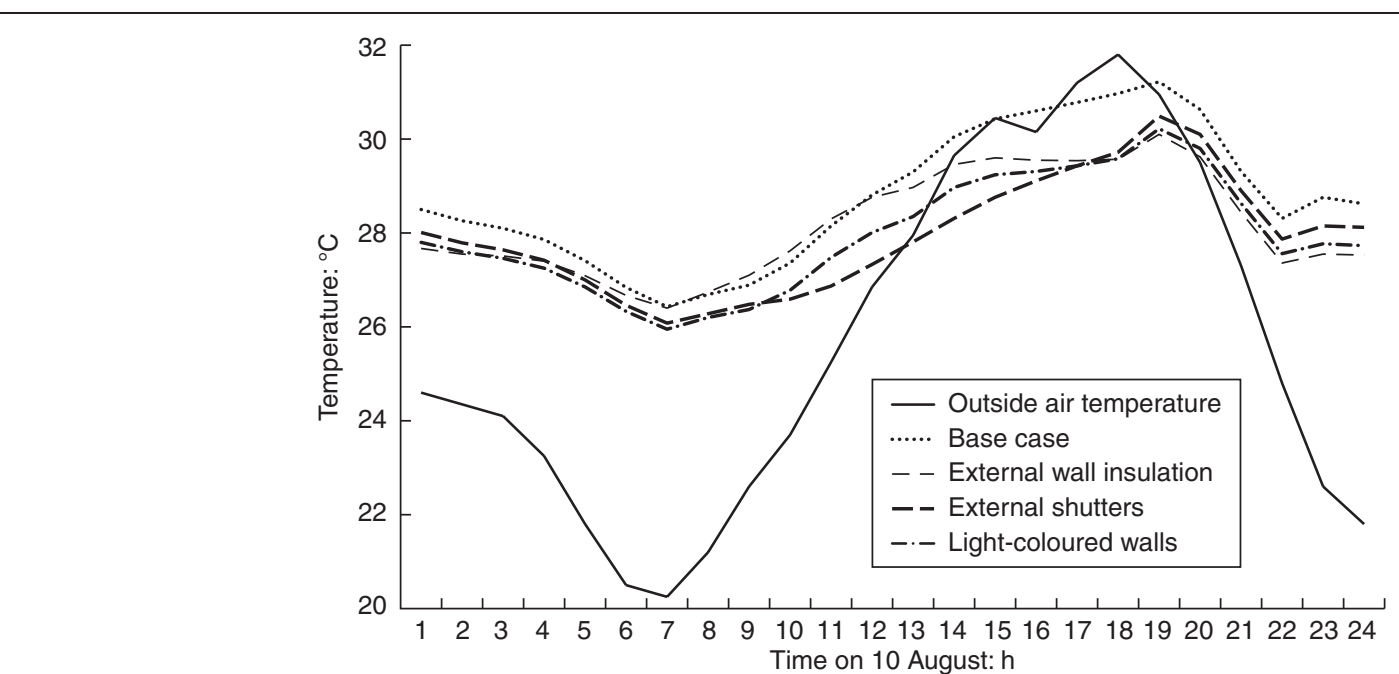

Figure 2. Single interventions: effect on house I, bedroom I

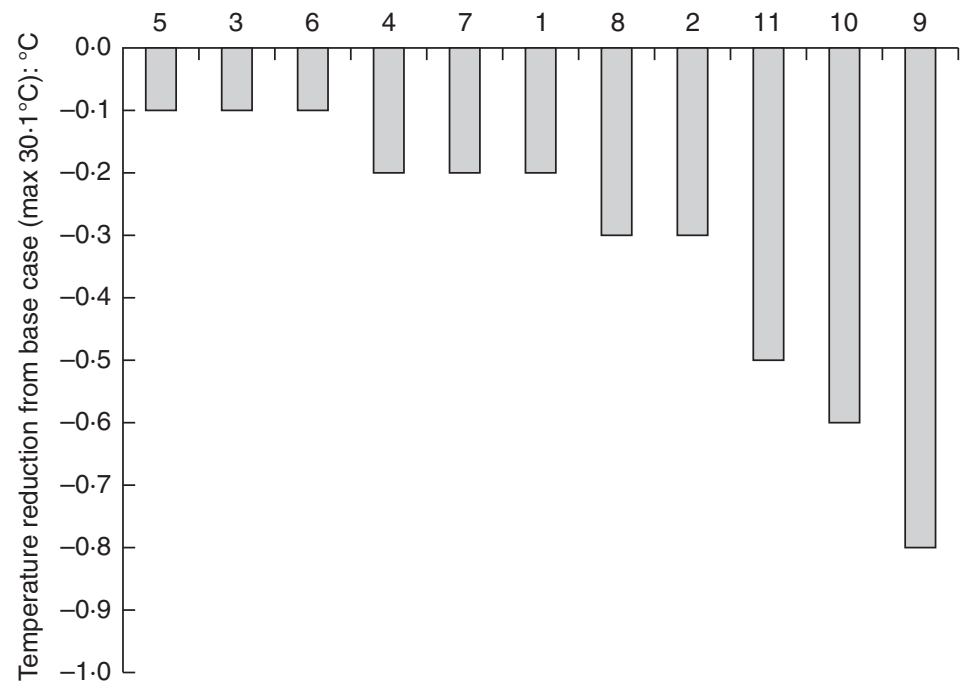


No single measure is capable of reducing the internal temperatures sufficiently to tackle the overheating problem, so a series of combined or clustered interventions were also then considered; these results will be presented in detail in a later paper.

\section{CONCLUSIONS}

These simulations were carried out using a test reference year (TRY) climate file for the 2080s, assuming a medium-high emissions scenario. The results show that the peak internal (operative) temperature can be easily reduced by purely passive means. Additional work on the effect of combining interventions has been completed and the results will be presented in full in a later paper.

Future work will explore the effect of interventions on a carefully selected range of dwelling types. A degree-hour method will yield information on the severity of overheating. Heat wave duration and its effect on different constructions will also be investigated, as will the adaptive opportunity of occupants to increased temperatures. The results of this work will contribute to other parts of the CREW project as well as contributing significantly to the future design and specification of heat-wave-resistant dwellings and other buildings.

\section{REFERENCES}

1. See www.extreme-weather-impacts.net

2. Hacker J. N., Holmes M. J., Belcher S. B. and Davies G. D. Climate Change and the Indoor Environment: Impacts and Adaptation. Chartered Institute of Building Services Engineers, London, 2005, Report TM36.

3. See www.energysavingtrust.org.uk

4. Chartered Institute of Building Services Engineers. CiBSE Guide A: Environmental Design. CIBSE, London, 2006.

5. American Society of Heating, Refrigerating and AirCONDITIONING ENGINEERS. ASHRAE Handbook: Fundamentals 2001. ASHRAE, Atlanta, GA, 2001.

6. Hulme M. et al. Climate Change Scenarios for the United Kingdom: The UKCIP02 Scientific Report. Tyndall Centre for Climate Change Research, Norwich, 2002.

\section{What do you think?}

To comment on this paper, please email up to 500 words to the editor at journals@ice.org.uk

Proceedings journals rely entirely on contributions sent in by civil engineers and related professionals, academics and students. Papers should be 2000-5000 words long, with adequate illustrations and references. Please visit www.thomastelford.com/journals for author guidelines and further details. 